\title{
Changes in MLST profiles and biotypes of Corynebacterium diphtheriae isolates from the diphtheria outbreak period to the period of invasive infections caused by nontoxigenic strains in Poland (1950-2016)
}

\author{
Urszula Czajka ${ }^{\dagger}$, Aldona Wiatrzyk ${ }^{\dagger}$, Ewa Mosiej, Kamila Formińska and Aleksandra A. Zasada*
}

\begin{abstract}
Background: Corynebacterium diphtheriae is a re-emerging pathogen in Europe causing invasive infections in vaccinated persons and classical diphtheria in unvaccinated persons. In the presented study we analysed genetic changes in C. diphtheriae isolates collected in Poland from the period before the introduction of the mass anti-diphtheria vaccination to the present time when over $98 \%$ of the population is vaccinated.

Methods: A total of 62 C. diphtheriae isolates collected in the 1950s-1960s, 1990s and 2000-2016 in Poland were investigated. Examined properties of the isolates included toxigenic status, presence of tox gene, biotype, MLST type (ST) and type of infection.

Results: A total of 12 sequence types (STs) were identified among the analysed C. diphtheriae isolates. The highest variability of STs was observed among isolates from diphtheria and asymptomatic carriers collected in the XX century. Over 95\% of isolates collected from invasive and wound infections in 2004-2016 belonged to ST8. Isolates from the XX century represented all four biotypes: mitis, gravis, intermedius and belfanti, but the belfanti biotype appeared only after the epidemic in the 1990s. All except three isolates from the XXI century represented the biotype gravis.

Conclusions: During a diphtheria epidemic period, non-epidemic clones of $C$. diphtheriae might also disseminate and persist in a particular area after the epidemic. An increase of the anti-diphtheria antibody level in the population causes not only the elimination of toxigenic strains from the population but may also influence the reduction of diversity of $C$. diphtheriae isolates. MLST types do not reflect the virulence of isolates. Each ST can be represented by various virulent variants representing various pathogenic capacities, for example toxigenic non-invasive, nontoxigenic invasive and nontoxigenic non-invasive.
\end{abstract}

Keywords: Corynebacterium diphtheriae, Diphtheria, Invasive infections, MLST

\footnotetext{
* Correspondence: azasada@pzh.gov.pl

${ }^{\dagger}$ Equal contributors

Department of Vaccines and Sera Evaluation, National Institute of Public

Health - National Institute of Hygiene, Chocimska 24, 00-791 Warsaw, Poland
}

\section{$\int$ Biomed Central}

(c) The Author(s). 2018 Open Access This article is distributed under the terms of the Creative Commons Attribution 4.0 International License (http://creativecommons.org/licenses/by/4.0/), which permits unrestricted use, distribution, and reproduction in any medium, provided you give appropriate credit to the original author(s) and the source, provide a link to the Creative Commons license, and indicate if changes were made. The Creative Commons Public Domain Dedication waiver (http://creativecommons.org/publicdomain/zero/1.0/) applies to the data made available in this article, unless otherwise stated. 


\section{Background}

Before the introduction of the mass anti-diphtheria vaccination the bacterium Corynebacterium diphtheriae inspired fear and was called "the strangling angel" of children because it was a major killer of children occurring in epidemics of diphtheria that resulted in thousands of deaths. The name 'strangling angel' of children arose from the wing-shaped pseudomembranes that form in the oropharynx. Dislodgment and impaction of these pseudomembranes caused acute airway obstruction and sudden death [1]. During the course of the disease toxin-producing (toxigenic) C. diphtheriae locally colonise the mucosa and the produced toxin is absorbed into the bloodstream and distributed throughout the whole organism. It causes early damage to the fibres of the cardiac muscle and its inflammation, conduction disorders and, possibly, heart block as well as demyelination of nerves which leads to the paralysis of the palate and ocular muscles [2].

After the introduction of the common anti-diphtheria vaccination in Europe the number of diphtheria cases decreased extremely. But in the 1990s a big epidemic occurred in the Newly Independent States of the Former Soviet Union (NIS) which affected all European countries. During this epidemic most cases were recorded not in children but in adults [3]. Subsequently, at the end of the 1990s C. diphtheriae invasive infections started to emerge in Europe and America. The majority of them are bacteraemia and endocarditis caused by nontoxigenic strains with the mortality rate reaching over $40 \%$ [4-10].

In Poland the last case of diphtheria was recorded in 2000 and the first invasive infection caused by nontoxigenic $C$. diphtheriae was reported in 2004 [11]. From that time such infections are recorded every year [4].

In this study we analyse genetic changes in $C$. diphtheriae isolates collected in Poland from the 1950s - before the introduction of the mass anti-diphtheria vaccination to 2016 when over $98 \%$ of the population is vaccinated. Results of the study might shed some light on the dissemination and evolution of $C$. diphtheriae in response to increasing anti-diphtheria immunity in the population after epidemic waves and after mass vaccination.

\section{Methods}

\section{Bacterial isolates}

A total of $62 C$. diphtheriae isolates were investigated from the strain collection of the National Institute of Public Health - National Institute of Hygiene (Poland). Among them eight were isolated from respiratory diphtheria in the 1950s-1960s, three were isolated from respiratory diphtheria in the $1990 \mathrm{~s}$, six were isolated from currieries in the 1960s, 1997, 2000 and 2001, 28 were isolated from invasive infections (bacteraemia and endocarditis) in 2004-2016, 16 were isolated from local infections (wound infections) in 2004-2016 and one was isolated in 2015 with no data concerning the type of infection. The group of isolates from 2000 to 2016 includes all of the $C$. diphtheriae isolates collected in Poland from the beginning of 2000 to June 2016 (except one isolate from 2014 that is missing). There are no identified epidemiological links among cases of $C$. diphtheriae infection in this period. The isolates were collected in various parts of Poland (Table 1). The city where $C$. diphtheriae was isolated is not always a home city of the patient because collected clinical samples are usually sent to diagnostic centres located in bigger cities. Isolates from the 1950s-1990s are the only isolates from that period in the NIPH-NIH collection without any data concerning epidemiological links.

\section{Biotyping and toxigenicity testing}

The isolates were biotyped using the API Coryne test (BioMerieux, France) according to the manufacturer's instruction. Toxigenicity was determined by conventional and modified Elek tests according to the WHO manual [12]. The presence of the diphtheria toxin gene was investigated by PCR as described previously [13].

\section{DNA extraction}

DNA for all molecular tests was extracted using DNeazy Blood and Tissue Kit (Qiagen, Germany) according to the manufacturer's instruction for gram-positive bacteria.

\section{Multilocus sequence typing}

The Multilocus sequence typing (MLST) was conducted as described by Bolt et al. [14]. Seven housekeeping genes (atpA, dnaE, dnaK, fusA, leuA, odhA and rpoB) were amplified by PCR, and sequenced and compared with the sequences submitted to the MLST database website (http://pubmlst.org/cdiphtheriae/) to determine sequence types (STs). The clonal relationship between isolates under study was visualised by constructing the minimum spanning tree based on the categorical clustering of STs using BioNumerics version 6.6 software (Applied Maths, Belgium).

\section{Results}

Among 62 C. diphtheriae isolates investigated 11 were toxigenic. The toxigenic isolates were collected in the 1950s, before the introduction of the common antidiphtheria vaccination in Poland, and in the 1990s, during the epidemic in the former Soviet Union. Non-toxigenic toxin gene bearing isolates (NTTB) were not detected in the examined collection. The collection of isolates includes all biotypes: mitis, gravis, belfanti and intermedius. However, the majority of isolates belong to the biotype gravis - 48 of them. Nine isolates belong to the biotype mitis, three to intermedius and two to belfanti. 
Table 1 Corynebacterium diphtheriae isolates in the presented study

\begin{tabular}{|c|c|c|c|c|c|c|c|}
\hline Isolate ID & Biotype & Toxigenicity status & MLST type & Allelic profile & Year of isolation & City of isolation & Site of isolation or disease \\
\hline $78 / E$ & gravis & - & ST8 & $3-5-6-5-3-3-6$ & 2016 & Kędzierzyn-Koźle & Blood \\
\hline 77/E & gravis & - & ST8 & $3-5-6-5-3-3-6$ & 2016 & Nowa Sól & Wound \\
\hline 76/E & gravis & - & ST8 & $3-5-6-5-3-3-6$ & 2016 & Łódź & Wound \\
\hline 75/E & gravis & - & ST8 & $3-5-6-5-3-3-6$ & 2016 & Bydgoszcz & Wound \\
\hline 74/E & mitis & - & ST407 (new) & $3-5-3-6-30-3-2$ & 2016 & Nowa Sól & Wound \\
\hline 73/E & gravis & - & ST8 & $3-5-6-5-3-3-6$ & 2016 & Piotrków Trybunalski & Blood \\
\hline 72/E & gravis & - & ST8 & $3-5-6-5-3-3-6$ & 2015 & Ostrołęka & NK \\
\hline $71 / \mathrm{E}$ & gravis & - & ST8 & $3-5-6-5-3-3-6$ & 2015 & Warszawa & Wound \\
\hline 70/E & gravis & - & ST8 & $3-5-6-5-3-3-6$ & 2015 & Warszawa & Blood \\
\hline 69/E & gravis & - & ST8 & $3-5-6-5-3-3-6$ & 2015 & Olsztyn & Blood \\
\hline 68/E & gravis & - & ST8 & $3-5-6-5-3-3-6$ & 2015 & Toruń & Blood \\
\hline 67/E & gravis & - & ST8 & $3-5-6-5-3-3-6$ & 2015 & Nowa Sól & Wound \\
\hline 66/E & gravis & - & ST8 & $3-5-6-5-3-3-6$ & 2015 & Kielce & Blood \\
\hline 65/E & gravis & - & ST8 & $3-5-6-5-3-3-6$ & 2015 & Warszawa & Wound \\
\hline $54 / \mathrm{E}$ & gravis & - & ST8 & $3-5-6-5-3-3-6$ & 2015 & Warszawa & Wound \\
\hline $42 / E$ & gravis & - & ST8 & $3-5-6-5-3-3-6$ & 2014 & Słupsk & Blood \\
\hline $41 / \mathrm{E}$ & gravis & - & ST8 & $3-5-6-5-3-3-6$ & 2014 & Warszawa & Blood \\
\hline 40/E & gravis & - & ST8 & $3-5-6-5-3-3-6$ & 2014 & Warszawa & Blood \\
\hline 39/E & gravis & - & ST8 & $3-5-6-5-3-3-6$ & 2013 & Gdynia & Wound \\
\hline 38/E & gravis & - & ST8 & $3-5-6-5-3-3-6$ & 2013 & Słupsk & Blood \\
\hline 37/E & gravis & - & ST8 & $3-5-6-5-3-3-6$ & 2012 & Poznań & Blood \\
\hline 36/E & gravis & - & ST8 & $3-5-6-5-3-3-6$ & 2012 & Warszawa & Wound \\
\hline 35/E & gravis & - & ST8 & $3-5-6-5-3-3-6$ & 2012 & Gdańsk & Blood \\
\hline 34/E & gravis & - & ST8 & $3-5-6-5-3-3-6$ & 2011 & Kraków & Blood \\
\hline 33/E & gravis & - & ST8 & $3-5-6-5-3-3-6$ & 2011 & Radom & Blood \\
\hline 32/E & gravis & - & ST8 & $3-5-6-5-3-3-6$ & 2011 & Sosnowiec & Blood \\
\hline $31 / E$ & gravis & - & ST8 & $3-5-6-5-3-3-6$ & 2010 & Legnica & Blood \\
\hline 30/E & gravis & - & ST8 & $3-5-6-5-3-3-6$ & 2010 & Gdynia & Blood \\
\hline 29/E & gravis & - & ST8 & $3-5-6-5-3-3-6$ & 2010 & Gdynia & Wound \\
\hline 28/E & gravis & - & ST8 & $3-5-6-5-3-3-6$ & 2010 & Bydgoszcz & Blood \\
\hline 27/E & mitis & - & ST392 (new) & $3-46-3-3-30-3-2$ & 2010 & Bydgoszcz & Wound \\
\hline 26/E & gravis & - & ST8 & $3-5-6-5-3-3-6$ & 2009 & Sosnowiec & Blood \\
\hline 25/E & gravis & - & ST8 & $3-5-6-5-3-3-6$ & 2009 & Kraków & Blood \\
\hline 24/E & gravis & - & ST8 & $3-5-6-5-3-3-6$ & 2009 & Gdynia & Blood \\
\hline 23/E & gravis & - & ST8 & $3-5-6-5-3-3-6$ & 2008 & Warszawa & Wound \\
\hline 21/E & gravis & - & ST8 & $3-5-6-5-3-3-6$ & 2008 & Gdynia & Blood \\
\hline 20/E & gravis & - & ST8 & $3-5-6-5-3-3-6$ & 2008 & Bydgoszcz & Blood \\
\hline 19/E & gravis & - & ST8 & $3-5-6-5-3-3-6$ & 2008 & Rzeszów & Blood \\
\hline 18/E & gravis & - & ST8 & $3-5-6-5-3-3-6$ & 2007 & Gdynia & Blood \\
\hline 17/E & gravis & - & ST8 & $3-5-6-5-3-3-6$ & 2007 & Bydgoszcz & Wound \\
\hline 16/E & gravis & - & ST8 & $3-5-6-5-3-3-6$ & 2007 & Warszawa & Wound \\
\hline 15/E & gravis & - & ST8 & $3-5-6-5-3-3-6$ & 2007 & Bydgoszcz & Wound \\
\hline 14/E & gravis & - & ST8 & $3-5-6-5-3-3-6$ & 2007 & Gdynia & Blood \\
\hline 13/E & gravis & & ST8 & $3-5-6-5-3-3-6$ & 2006 & Bydgoszcz & Blood \\
\hline
\end{tabular}


Table 1 Corynebacterium diphtheriae isolates in the presented study (Continued)

\begin{tabular}{|c|c|c|c|c|c|c|c|}
\hline Isolate ID & Biotype & Toxigenicity status & MLST type & Allelic profile & Year of isolation & City of isolation & Site of isolation or disease \\
\hline $12 / \mathrm{E}$ & gravis & - & ST8 & $3-5-6-5-3-3-6$ & 2004 & Warszawa & Blood \\
\hline $11 / \mathrm{D}$ & belfanti & - & ST65 & $6-7-10-12-9-12-15$ & 2001 & Suwałki & Carrier \\
\hline $10 / C$ & belfanti & - & ST69 & $6-7-21-17-9-7-11$ & 2000 & Suwałki & Carrier \\
\hline $6 / B$ & gravis & - & ST32 & $3-1-18-4-13-3-5$ & 1997 & Otmuchów & Carrier \\
\hline $7 / B$ & mitis & + & ST44 & $14-2-23-1-2-14-2$ & 1990s & NK & Diphtheria \\
\hline $8 / B$ & intermedius & + & ST44 & $14-2-23-1-2-14-2$ & $1990 \mathrm{~s}$ & NK & Diphtheria \\
\hline $9 / B$ & mitis & + & ST44 & $14-2-23-1-2-14-2$ & $1990 \mathrm{~s}$ & NK & Diphtheria \\
\hline $5 / A$ & gravis & + & ST63 & $5-6-7-1-3-5-8$ & $1960 \mathrm{~s}$ & NK & Diphtheria \\
\hline $4 / A$ & intermedius & + & ST155 & $4-2-2-1-2-2-2$ & $1960 \mathrm{~s}$ & NK & Diphtheria \\
\hline $1 / \mathrm{A}$ & mitis & - & ST26 & $8-2-16-1-3-3-12$ & $1960 \mathrm{~s}$ & NK & Carrier \\
\hline $2 / \mathrm{A}$ & mitis & - & ST26 & $8-2-16-1-3-3-12$ & $1960 \mathrm{~s}$ & NK & Carrier \\
\hline $3 / A$ & mitis & - & ST26 & $8-2-16-1-3-3-12$ & $1960 \mathrm{~s}$ & NK & Carrier \\
\hline $62 / 5$ & gravis & + & ST25 & $5-6-7-6-6-3-8$ & $1950 \mathrm{~s}$ & NK & Diphtheria \\
\hline $59 / 5$ & mitis & + & ST25 & $5-6-7-6-6-3-8$ & $1950 \mathrm{~s}$ & NK & Diphtheria \\
\hline $58 / \mathrm{S}$ & gravis & + & ST25 & $5-6-7-6-6-3-8$ & $1950 \mathrm{~s}$ & NK & Diphtheria \\
\hline $57 / 5$ & gravis & + & ST25 & $5-6-7-6-6-3-8$ & $1950 \mathrm{~s}$ & NK & Diphtheria \\
\hline $56 / S$ & mitis & + & ST393 (new) & $8-3-5-2-1-4-4$ & $1950 \mathrm{~s}$ & NK & Diphtheria \\
\hline $55 / \mathrm{S}$ & intermedius & + & ST155 & $4-2-2-1-2-2-2$ & $1950 \mathrm{~s}$ & NK & Diphtheria \\
\hline
\end{tabular}

NK not known

Figure 1 presents the distribution of $C$. diphtheriae biotypes in time periods with consideration of the toxigenicity of the isolates.

A total of 12 sequence types (STs) were identified among the $62 \mathrm{C}$. diphtheriae analysed. Three of them: ST392, ST393 and ST407 were new types. The new types have been deposited in the $C$. diphtheriae MLST database (http://pubmlst.org/cdiphtheriae/). All three new types were represented by the mitis biotype and were isolated from a wound infection in 2010, respiratory diphtheria in the 1950s and a wound infection in 2016, respectively. Isolates from the 1950s-1960s represented ST25 (three gravis and one mitis), ST26 (three mitis), ST63 (one gravis), ST155 (two intermedius) and ST393 (one mitis) mentioned above. All isolates from this group except three mitis representing ST26 were toxigenic. Among four isolates from the 1990s three (two mitis and one intermedius) belonged to ST44 and were toxigenic, and one gravis belonged to ST32 and was nontoxigenic. Two nontoxigenic isolates from 2000 and

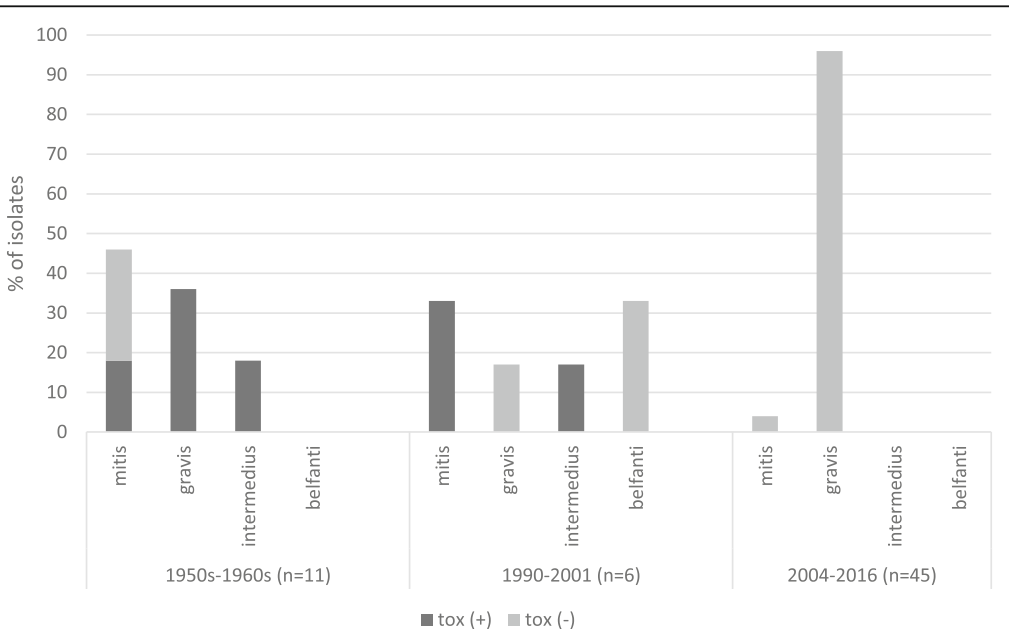

Fig. 1 Distribution of $C$. diphtheriae biotypes in different time periods with consideration of toxigenicity of the isolates ( $\mathrm{n}$ - number of isolates included in the study) 
2001, representing the belfanti biotype, belonged to ST69 and ST65, respectively. All but three isolates from 2004 to 2016 belonged to ST8. All of these ST8 were biotype gravis. The three other isolates from this time period belonged to ST67 and, mentioned above, ST392 and ST407, and represented the biotype mitis.

Figure 2 presents a genetic correlation among the investigated isolates. The two closest related isolates were ST392 and ST407 isolated in 2010 and 2016, respectively, from wound infections, which share five of seven MLST loci. ST407 shares three loci with ST8 which represents the largest group of isolates collected in the same time period. Isolates from the 1990s-2001 and the 1950s-1960s showed significant genetic diversity. Figure 3 presents the distribution of STs by type of infections.

\section{Discussion}

The number of diphtheria cases has been strongly limited in Europe due to the common anti-diphtheria vaccination. But the disease still exists in the world in endemic areas where diphtheria outbreaks occur. For example, according to World Health Organization data in 2015 diphtheria was recorded, among others places, in Madagascar - 1627 cases, The Lao People's Democratic Republic - 194 cases, Myanmar -87 cases, Haiti -32 cases, Iran -28 cases, Nepal - 26 cases, Thailand - 19 cases, but also in France - 14 cases and Germany - 14 cases [15]. The number of diphtheria cases in Europe increases every year [16]. The possible explanation for this is a decreasing level of the anti-diphtheria antibody with the increasing of age, the migration of people between Europe and diphtheria endemic countries and an increasing number of parents refusing to have their children vaccinated [16-21]. Moreover, life-threating invasive infections caused by nontoxigenic $C$. diphtheriae have appeared in Europe with increasing frequency $[4,7,22-24]$. All these facts point to the necessity of monitoring the spread and evolutional changes of $C$. diphtheriae in Europe.

When analysing the spread and evolution of $C$. diphtheriae in Poland it is worth keeping in mind the socio-demographical situation in this area, such as a limited number of refugees and immigrants, and not very strong anti-vaccination movements, yet. Due to high vaccination coverage there have been no diphtheria cases for over 15 years. C. diphtheriae strains circulating in Poland have been under strong selective pressure caused by the anti-diphtheria antibody level in the population. Moreover, a limited number of refugees and immigrants might be related to a limited number of strains imported from other regions of the world, including diphtheria endemic areas.

The presented MLST analysis of the $C$. diphtheriae collection revealed great genetic diversity among isolates from the 1950s-1960s. In this time period diphtheria was a common disease in Poland. In 1950-1956 there was a large diphtheria epidemic and, during its peak, the number of cases ranged from more than 24,000 to nearly $44,000[25,26]$. The genetic diversity of toxigenic $C$. diphtheriae strains during an epidemic period is unusual. In other countries, like Algeria, the Russian Federation and other NIS, the Dominican Republic, and Haiti, epidemic waves were related to the domination of a particular genotype of $C$. diphtheriae [14, 27]. However, because of a limited number of isolates from that period

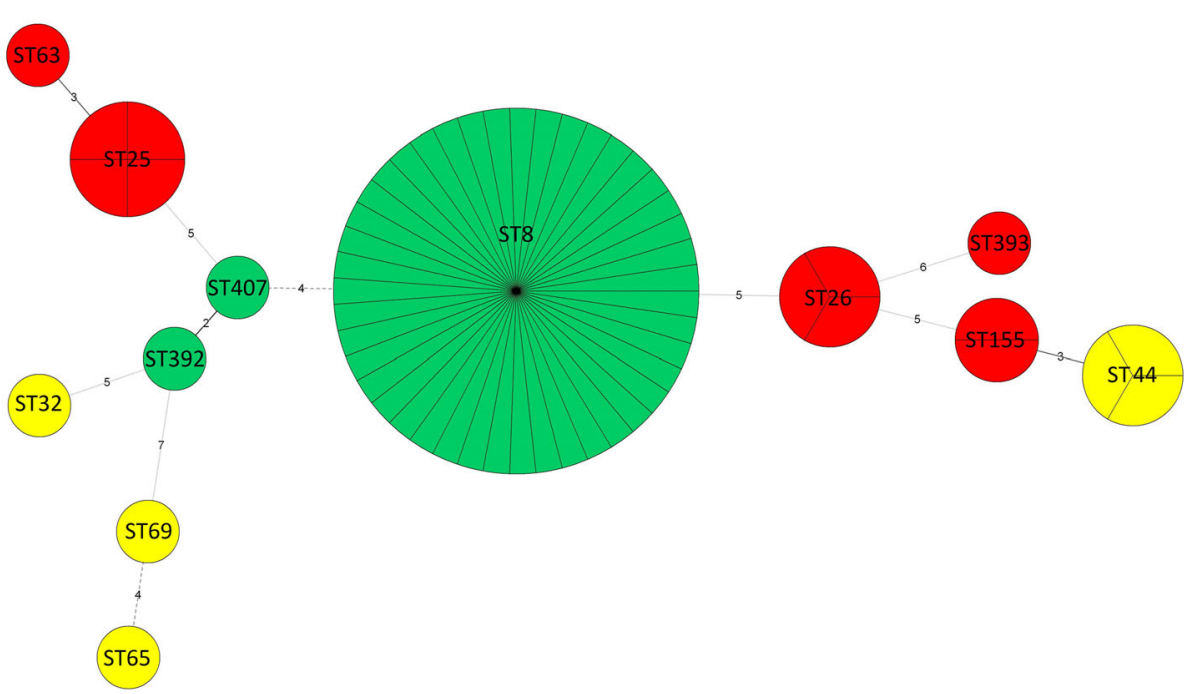

Fig. 2 Minimum spanning tree of the MLSTs of the 62 C. diphtheriae isolates. Each circle corresponds to an ST. The area of each circle corresponds to the number of isolates. Each ST is colour coded according to its corresponding time period of isolation: red - 1950s-1960s, yellow - 1990s-2001, green - 2004-2016. The relationships between the isolates are indicated by the connections between the isolates and the lengths of the branches linking them. The numbers between the circles indicate the number of allelic differences 


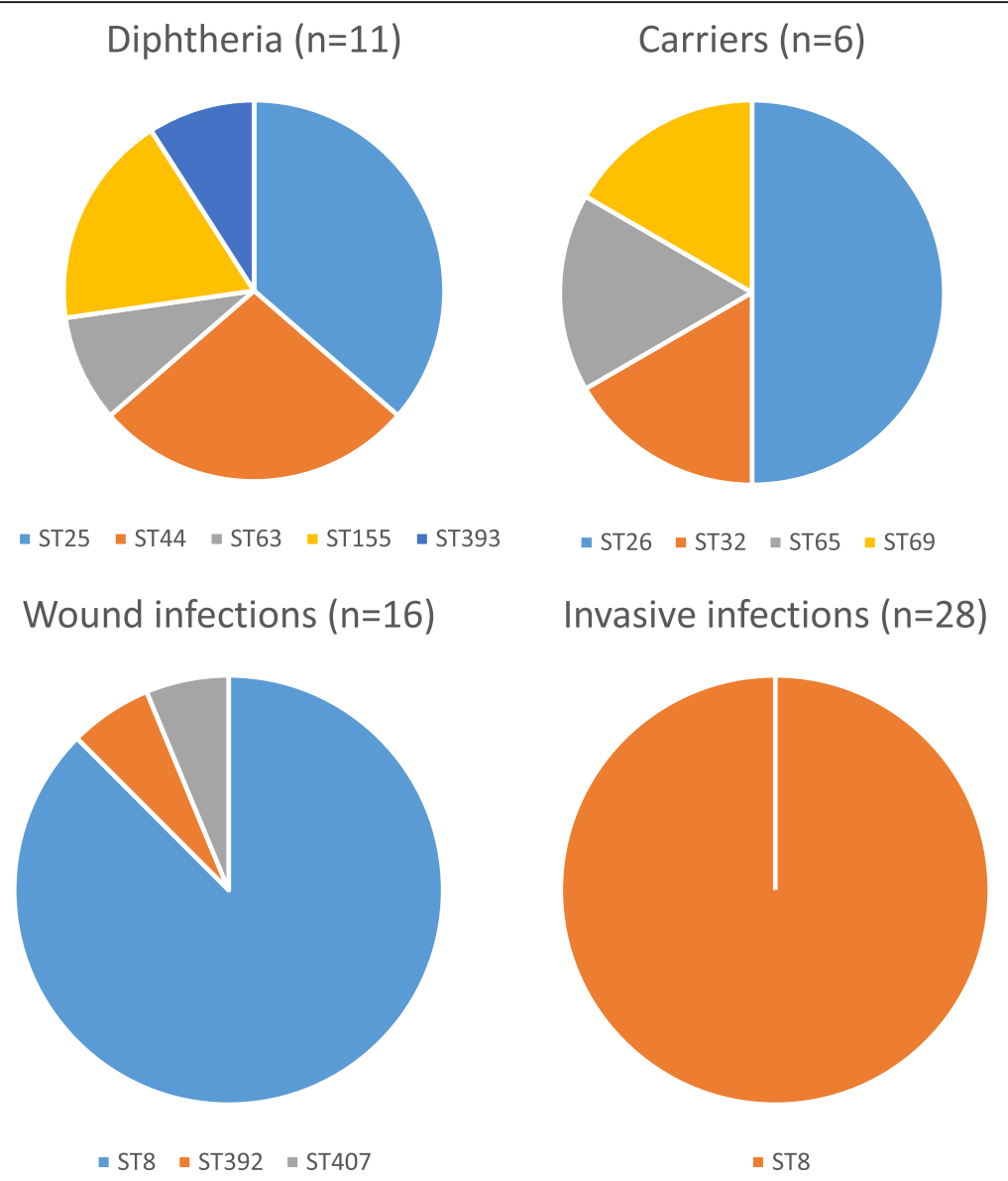

Fig. 3 Distribution of STs by type of infections ( $n$ - number of isolates included in the study). The charts do not include isolate 72/E (site of isolation is not known)

we cannot exclude domination of a particular ST in Poland in 1950s-1960s. Due to the introduction of the mass anti-diphtheria vaccination in the whole area of Poland in 1954 the number of cases started decreasing rapidly. The increasing number of vaccinated persons in the population was related to replacing toxigenic strains with nontoxigenic as shown in Fig. 1. Interestingly, biotype belfanti, which is typically nontoxigenic, probably appeared in Poland after the epidemic in the 1990s. Similarly, in Algeria C. diphtheriae biotype belfanti was not isolated during the epidemic in 1992-1999. Then, in the post-epidemic period, the number of belfanti isolates started to increase reaching almost $100 \%$ of isolates in 2007-2015 [27].

In the 1990s there was a large epidemic in the former Soviet Union (FSU) which also affected other European countries. In Poland, several cases were recorded during this time. All toxigenic isolates from this time in the collection represented ST44. Interestingly, the clonal complex recognised as associated with the FSU epidemic composed of ST8, ST12, ST52 and ST66 isolates [14]. ST44 did not share any allele with the STs representing
FSU epidemic clonal complex but it shared three alleles with ST155 toxigenic isolates collected in the 1950s1960s in Poland. Borisova et al. [28] identified ST44 among eight STs of toxigenic $C$. diphtheriae isolated in Russia in 2002-2012. This might indicate that during the FSU epidemic diphtheria strains disseminated not only from the NIS to Europe but also from European countries, particularly Poland, to the NIS, where they have persisted till now. It is worth mentioning that after the fall of the Soviet Union in 1991 many people from Russia and other NIS travelled to Poland. It might enhance the transmission of C. diphtheriae strains between Poland and NIS.

On the other hand, ST8 isolates dominating in 20042016 in Poland and causing invasive infections also dominated in Russia in 2002-2012 together with two other STs causing diphtheria [28]. In both countries ST8 was represented by the gravis biotype, but in Poland the isolates were nontoxigenic. As ST8 was present in Russia for decades and it appeared in Poland 13 years ago, it might be hypothesised that the strain ST8 was transferred from Russia to Poland where it lost its ability to produce toxins as a result of environmental pressure of 
the vaccinated population $(96 \%-99 \%$ of the Polish population received at least three doses of the anti-diphtheria vaccine [2]). Another possibility is an independent parallel evolution of $C$. diphtheriae strains in Poland and Russia. The latter hypothesis is supported by the fact that no NTTB isolates were identified in the examined collection. Mutations resulting in tox gene inactivation seem to be quite common in $C$. diphtheriae after epidemic waves [29] that can be an adaptation of the strains to the colonisation of the population with an increasing anti-diphtheria antibody level. We cannot exclude that NTTB strains were circulated in Poland before 2000 because of a limited number of investigated isolates from this period. But all isolates collected in Poland in 20002016 were included in the study which makes this group of isolates fully representative. We did not detect tox gene in the Polish ST8 isolates.

The ST8 nontoxigenic isolates are widespread in Poland [4]. Over 95\% of C. diphtheriae isolates collected in various parts of Poland in 2004-2016 belong to this ST (Table 1). Moreover, all of the invasive infections were caused by ST8. However, isolation of one ST407 in 2016 and one ST392 in 2010 indicates that STs other than ST8 are also present in the Polish population, but their dissemination ability or pathogenic properties (or both) are significantly lower than ST8 isolates. Unfortunately, the status of the asymptomatic carriage of $C$. diphtheriae in the Polish population, that could provide information about non-pathogenic strains, is unknown because throat swabs are not routinely examined for this bacterium currently. Figure 3 presents the distribution of STs of isolates investigated in this study by type of infections. Despite a limited number of isolates collected in the period before the introduction of the antidiphtheria vaccination, a great diversity of $C$. diphtheriae circulating in the population is visible. In that period at least three biotypes (mitis, intermedius, gravis) and various STs circulated, both toxigenic and non-toxigenic. Introduction of compulsory vaccinations against diphtheria caused not only the elimination of toxigenic strains but also reduced the diversity of $C$. diphtheriae isolates.

MLST is a valuable tool for the evolutionary investigation of bacteria as well as for tracking the spread of important clones. But this method offers limited usefulness for identification of hypervirulent clones. It is because MLST data are based on changes in the core genome whereas changes in virulence correspond primarily to changes in the accessory genome [30]. Sengal et al. [31] revealed that approximately one-third of the $C$. diphtheriae genome encodes accessory genes that vary widely between strains. The strains within one ST may differ in the presence of up to 290 genes. On the other hand, results of our study and the study presented by Borisova et al. [28] clearly suggest that $C$. diphtheriae
ST8 may possess better adaptive properties and abilities to disseminate in current populations which seem to be independent from pathogenic properties. As the virulence factors determining invasive properties are not known, there is a possibility that ST8 strains circulating in Poland are represented by various virulent variants. We can assume that at least three virulence variants of ST8 circulate in Poland and Russia: toxigenic non-invasive (diphtheria), nontoxigenic invasive (bacteraemia, endocarditis) and nontoxigenic non-invasive (wound infection).

\section{Conclusions}

The presented study has two main limitations: a relatively small number of isolates from the diphtheria epidemic periods (before the year 2000) and a lack of isolates from asymptomatic carriers after 2000. However, taking together the results of our study and results published by other researchers we can suggest that (i) nontoxigenic strains, particularly NTTB and the belfanti biotype, appear mainly after epidemic waves as a result of the increase of the anti-diphtheria antibody level in the population; (ii) during a diphtheria epidemic period non-epidemic clones of $C$. diphtheriae might also disseminate and persist on a particular area after the epidemic; (iii) increase of the anti-diphtheria antibody level in the population causes not only elimination of toxigenic strains but may also influence a reduction of diversity of $C$. diphtheriae isolates; (iv) each ST can be represented by various virulent variants. For these reasons it seems to be impossible to identify hypervirulent clones by MLST. Nevertheless, MLST might be useful in the identification of clones revealing better dissemination properties. To monitor effectively the spread of $C$. diphtheriae strains in Europe it is necessary to know STs circulating in each country. For further discrimination of STs, recognition of $C$. diphtheriae virulence determinants is necessary.

\section{Abbreviations}

FSU: The Former Soviet Union; MLST: Multilocus Sequence Typing; NIS: Newly Independent States of the Former Soviet Union; NTTB: Nontoxigenic toxin gene bearing; ST: Sequence Type

\section{Acknowledgments \\ The authors thank to Laboratory of Bacteriological Diagnostics, Department of Bacteriology NIPH-NIH for providing them with several $\mathrm{C}$. diphtheriae isolates.}

\section{Funding}

This study was supported by the National Institute of Public Health National Institute of Hygiene internal-grant (no. 1/EM/2017).

\section{Availability of data and materials}

All data generated or analysed during this study are included in this published article.

\section{Authors' contributions}

UC and AW participated equally in the study, conducted MLST; EM conducted phylogenetic analysis; KF conducted phenotypic tests and DNA 
extraction; AAZ designed the study, analysed results and wrote the manuscript. All authors read and approved the final manuscript.

\section{Ethics approval and consent to participate}

Ethical approval was not required for the use of clinical samples because al the investigated isolates were taken as a part of standard care (diagnostic purposes). The samples were not collected for research purposes.

\section{Consent for publication}

Not applicable.

\section{Competing interests}

The authors declare that they have no competing interests.

\section{Publisher's Note}

Springer Nature remains neutral with regard to jurisdictional claims in published maps and institutional affiliations.

\section{Received: 4 April 2017 Accepted: 28 February 2018}

\section{Published online: 09 March 2018}

\section{References}

1. Byard RW. Diphtheria - 'the strangling angel' of children. J Forensis Legal Med. 2013;20:65-8.

2. Zasada AA. Corynebacterium diphtheriae infections currently and in the past. Przegl Epidemiol. 2015;69:439-44.

3. Galazka A, Dittmann S. The changing epidemiology of diphtheria in the vaccine era. J Infect Dis. 2000;181(Suppl 1):S2-9.

4. Zasada AA. Nontoxigenic highly pathogenic clone of Corynebacterium diphtheriae, Poland, 2004-2012. Emerg Infect Dis. 2013;19:1870-2.

5. De Winter LM, Bernard KA, Romney MC. Human clinical isolates of Corynebacterium diphtheriae and Corynebacterium ulcerans collected in Kanada form 1999 to 2003 but not fitting reporting criteria for cases of diphtheria. J Clin Microbiol. 2005;43:3447-9.

6. Gubler J, Huber-Schneider C, Gruner E, Altwegg M. An outbreak of nontoxigenic Corynebacterium diphtheriae infection: single bacterial clone causing invasive infection among Swiss drug users. Clin Infect Dis. 1998;27:1295-8.

7. Farfour E, Badell E, Zasada A, Hotzel H, Tomaso H, Guillot S, et al. Characterization and comparison of invasive Corynebacterium diphtheriae isolates from France and Poland. J Clin Microbiol. 2012;50:173-5.

8. Viguetti SZ, Pacheco LGC, Santos LS, Soares SC, Bolt F, Baldwin A, et al. Multilocus sequence types of invasive Coryenbacterium diphtheriae isolated in the Rio de Janeiro urban area, Brazil. Epidemiol Infect. 2012;140:617-20.

9. von Hunolstein C, Alfarone G, Scopetti F, Pataracchia M, La Valle R, Franchi $F$, et al. Molecular epidemiology and characteristics of Corynebacterium diphtheriae and Corynebacterium ulcerans strains isolated in Italy during the 1990s. J Med Microbiol. 2003;52:181-8.

10. Hirata Jr.R, Pereira GA, Filardy AA, Gomes DL, Damasco PV, Rosa AC, et al. Potential pathogenic role of aggregative-adhering Corynebacterium diphtheriae of different clonal groups in endocarditis. Braz J Med Biol Res 2008:41:986-991.

11. Zasada AA, Zaleska M, Podlasin RB, Seferyńska I. The first case of septicemia due to nontoxigenic Corynebacterium diphtheriae in Poland: case report. Ann Clin Microbiol Antimicrob. 2005;4:8

12. Efstratiou A, Maple C. Manual for the laboratory diagnosis of diphtheria. Available at: http://apps.who.int/iris/bitstream/10665/108108/1/ICP_EPI_038_ (C).pdf. Accessed 29 Mar 2017.

13. Zasada AA, Baczewska-Rej M, Wardak S. An increase in non-toxigenic Corynebacterium diphtheriae infections in Poland - molecular epidemiology and antimicrobial susceptibility of strains isolated from past outbreaks and those currently circulating in Poland. Int J Infect Dis. 2010;14:907-12.

14. Bolt F, Cassiday P, Tondella ML, De Zoysa A, Efstratiou A, Sing A, et al. Multilocus sequence typing identifies evidence for recombination and two distinct lineages of Conynebacterium diphtheriae. J Clin Microbiol. 2010:48:4177-85.

15. World Health Organization (WHO). Diphtheria reported cases. Geneva: WHO Available at: http://apps.who.int/immunization_monitoring/globalsummary/ timeseries/tsincidencediphtheria.html. Accessed 29 Mar 2017.

16. European Centre for Disease Prevention and Control (ECDC). Rapid risk assessment: a fatal case of diphtheria in Belgium. Available at: http://ecdc. europa.eu/en/publications/Publications/RRA-Diphtheria-Belgium.pdf. Accessed 29 Mar 2017
17. Both L, Collins S, De Zoysa A, White J, Mandal S. Efstratiou. A molecular and epidemiological review of toxigenic diphtheria infections in England between 2007 and 2013. J Clin Microbiol. 2015;53:567-72.

18. European Centre for Disease Prevention and Control (ECDC). Rapid risk assessment: cutaneous diphtheria among recently arrived refugees and asylum-seekers in the EU. Available at: http://ecdc.europa.eu/en/publications/ Publications/Diphtheria-cutaneous-EU-July-2015.pdf. Accessed 29 Mar 2017.

19. European Centre for Disease Prevention and Control (ECDC). Rapid risk assessment: a case of diphtheria in Spain. Available at: http://ecdc.europa. eu/en/publications/Publications/diphtheria-spain-rapid-risk-assessment-june2015.pdf. Accessed 29 Mar 2017.

20. Sane J, Sorvari T, Widerstrom M, Kauma H, Kaukoniemi U, Tarkka E, Puumalainen T, Kuusi M, Salminen M, Lyytikainen O. Respiratory diphtheria in an asylum seeker from Afghanistan arriving to Finland via Sweden, December 2015. Euro Surveill. 2016;21:pii=30105.

21. Zasada AA, Rastawicki W, Rokosz N, Jagielski M. Seroprevalence of diphtheria toxoid lgG antibodies in children, adolescents and adults in Poland. BMC Infect Dis. 2013:13:551.

22. Holfelder M, Bock-Hensley O, Lisson C, Funke G. Case report: fatal course of endocarditis following an infection with nontoxigenic Corynebacterium diphtheriae biotype var mitis. Euro Surveill. 2004;8:2397.

23. Reacher M, Ramsay M, White J, De Zoysa A, Efstratiou A, Mann G, et al. Nontoxigenic Corynebacterium diphtheriae: an emerging pathogen in England and Wales? Emerg Infect Dis. 2000;6:640-5.

24. Belko J, Wessel DL, Malley R. Endocarditis caused by Corynebacterium diphtheriae: case report and review of the literature. Pediatr Infect Dis J. 2000;19:159-63.

25. Błonica KJ. In: Kostrzewski J, editor. Choroby zakaźne w Polsce i ich zwalczanie w latach 1919-1962. Warszawa: PZWL; 1964. p. 96-117.

26. Błonica GA. In: Kostrzewski J, Magdzik W, Naruszewicz-Lesiuk D, editors. Choroby zakaźne i ich zwalczanie na ziemiach polskich w XX wieku. Warszawa: PZWL; 2001. p. 143-52.

27. Benamrouche N, Hasnaoui S, Badell E, Guettou B, Lazri M, Guiso N, et al. Microbiological and molecular characterization of Corynebacterium diphtheriae isolated in Algieria between 1992 and 2015. Clin Microbiol Infect. 2016;22:1005.e1-7.

28. Borisova O, Mazurova IK, Chagina IA, Pimenova AS, Donskikh EE, Aleshkin VA. Multilocus sequencing of Corynebacterium diphtheriae strains isolated in Russia in 2002-2012. Zh Mikorbiol Epidemiol Immunobiol. 2013;4:17-23.

29. Zakikhany K, Neal S, Efstratiou A. Emergence and molecular characterisation of non-toxigenic tox gene-bearing Corynebacterium diphtheriae biovar mitis in the United Kingdom, 2003-2012. Euro Surveill. 2014;19:pii=20819.

30. Turner KME, Feil EJ. The secret life of the multilocus sequence type. Int J Antimicrob Agents. 2007;29:129-35.

31. Sangal V, Blom J, Sutcliffe IC, von Hunolstein C, Burkovski A, Hoskisson PA. Adherence and invasive properties of Corynebacterium diphtheriae strains correlates with the predicted membrane-associated and secreted proteome. BMC Genomics. 2015:16:765.

\section{Submit your next manuscript to BioMed Central and we will help you at every step:}

- We accept pre-submission inquiries

- Our selector tool helps you to find the most relevant journal

- We provide round the clock customer support

- Convenient online submission

- Thorough peer review

- Inclusion in PubMed and all major indexing services

- Maximum visibility for your research

Submit your manuscript at www.biomedcentral.com/submit
) Biomed Central 